\title{
The Effects of Quantitative Gait Assessment and Botulinum Toxin A on Musculoskeletal Surgery in Children with Cerebral Palsy
}

\author{
By Guy Molenaers, MD, PhD, KaAt Desloovere, PhD, Guy Fabry, MD, PhD, and Paul De Cock, MD, PhD
}

Investigation performed at University Hospital Pellenberg, Pellenberg, Belgium

\begin{abstract}
Background: The limits of nonoperative treatment for children with cerebral palsy, including physical therapy and orthotics, commonly lead to orthopaedic surgical intervention. The purpose of the present study was to evaluate the influence of gait analysis and botulinum toxin type-A injections on the timing, prevalence, and frequency of orthopaedic surgery.
\end{abstract}

Methods: We performed a retrospective review of 424 children with cerebral palsy who had been born between 1976 and 1994. The children were divided into three groups: Group 1 comprised 122 patients who were managed throughout the entire study period according to best-practice guidelines in orthopaedics, Group 2 comprised 170 patients who were similarly managed but with input from gait analysis, and Group 3 comprised 132 patients who had gait analysis and also received botulinum toxin type-A injections. We analyzed the prevalence of orthopaedic surgical procedures at different ages (three to nine years) and the time to the first surgical procedure.

Results: The progression to orthopaedic surgery was significantly different among the three groups $(p<0.0001)$. The proportion of patients who had undergone at least one surgical procedure by the age of seven years was $52 \%$ (sixty-four of 122) for Group 1, 27\% (forty-six of 170) for Group 2, and 10\% (thirteen of 132) for Group 3. There was a delay in surgery in Group 2 as compared with Group 1 ( $p<0.00001$ at seven, eight, and nine years of age) and a significant decrease in the prevalence of orthopaedic surgical procedures for Group 3 as compared with Group 1 ( $p<$ 0.00001 at four to eight years of age) and Group 2 ( $p<0.0025$ at four to nine years of age).

Conclusions: In the treatment of children who have cerebral palsy, the introduction of gait analysis increases the age of the first orthopaedic surgical procedure and botulinum toxin type-A treatment delays and reduces the frequency of surgical procedures.

Level of Evidence: Therapeutic Level III. See Instructions to Authors for a complete description of levels of evidence.

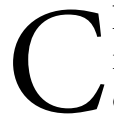
hildren with cerebral palsy present with a variety of motor problems that can change with growth and ated secondary problems typically cause gait disturbance. Primary motor problems are directly related to a lesion in the central nervous system and influence muscle tone (defined as a velocity-dependent increase in tonic stretch reflexes) $)^{5,6}$, balance, strength, and selective motor control of different muscle groups. Secondary problems, primarily static muscle contractures and osseous deformities, develop slowly over time in response to the primary motor problems and growth $^{3,7,8}$. Orthopaedic surgical intervention to improve gait should be postponed, if possible, until motion patterns are well established ${ }^{3,8-10}$. Newly developed motion patterns are characterized by inconsistency or large intrasubject variability ${ }^{3}$. Careful gait evaluation may define the age of consistent gait for normal children and for children with cerebral palsy ${ }^{11-15}$. Operative treatment before the attainment of a well-established gait pattern is associated with a higher risk of failure and relapse with less predictable results ${ }^{3,8-10}$. Therefore, it is generally recommended that surgical intervention to improve gait should be delayed until gait is well established as a stable motion pattern, usually between the ages of eight and ten years ${ }^{11-15}$.

Nonoperative options for the treatment of motor problems in patients with cerebral palsy include physical and occupational therapy, orthotics, serial casting, and oral medication. Physical and occupational therapy remain corner- 
The Journal of Bone \& JOINT SURgery • JBIS. ORG Volume 88-A · Number 1 · January 2006
EFFects of Gait Assessment and Botulinum Toxin A on Musculoskeletal Surgery in Cerebral Palsy stones in the treatment of cerebral palsy ${ }^{16-21}$. In addition to the importance of stretching, strengthening, and proprioceptive exercises in maximizing patient function, these exercises are crucial to optimizing the success of other medical and surgical interventions. The use of stretching casts reduces muscle contractures and has beneficial effects on gait ${ }^{22-26}$. Casting also may affect motor-neuron excitability in a hyperactive muscle group as increased muscle length and stretching of connective tissues result in spindle afferents being "unloaded" at a given joint position $^{3,6,27}$. Daytime and nighttime orthoses are utilized to help to delay the development of contractures, to enhance function, to provide biomechanically optimal alignment, and to allow proprioceptive training ${ }^{26,28,29}$. The use of orally administered medications, such as baclofen, diazepam, dantrolene sodium, and tizanidine, can be helpful in selected patients with cerebral palsy for whom generalized reduction in tone is desired $^{30,31}$. Operative treatment typically is indicated when major secondary problems are recognized and when there is an insufficient response to nonoperative treatment. The aim of operative treatment is to lengthen and/or transfer all major involved muscles and to correct all osseous deformities (to improve lever-arm dysfunction) during a single anesthetic procedure so that the lower extremity joints are balanced and realigned simultaneously.

Botulinum toxin type A (BoNTA) (BOTOX; Allergan, Irvine, California) is a relatively new treatment for children who have cerebral palsy. The selective and temporary chemical denervation of the muscle with use of this medication facilitates the direct treatment of primary motor problems by balancing muscle forces across joints ${ }^{32-38}$. On this basis, it may positively influence the pathologic process of cerebral palsy. To achieve the optimal response, early treatment with botulinum toxin type A is preferable ${ }^{39-42}$. The first clinical trial of botulinum toxin type A in patients with cerebral palsy was performed in 1993 by Koman et al. $^{32}$, who assessed the effectiveness of intramuscularly injected botulinum toxin type A in twenty-seven children with cerebral palsy. Clinical changes in gait and reduction in spasticity lasted three to six months. Later studies demonstrated similar positive short-term outcomes (at six months or less) following treatment with botulinum toxin type $\mathrm{A}^{33-38}$. However, there is a lack of long-term outcome studies of botulinum toxin type A treatment in children with cerebral palsy ${ }^{43}$.

There are clear advantages to delaying surgery until the patient is eight years of age or older. Before this age, the recurrence rate or the need for a secondary procedure for equinus gait increases in children who have undergone Achilles tendon-lengthening procedures ${ }^{3,9,10}$. Moreover, before the age of eight years, the gait of children with cerebral palsy is not yet well established and is characterized by inconsistency or large intrasubject variability, which complicates a clear recognition of all major problems in gait and motor function ${ }^{3}$. Delp et al. ${ }^{44}$ provided evidence that surgical procedures on soft tissue affect the moment-generating capacity, indicating that repeated muscle-lengthening should be avoided to prevent weakness. Wenger and Rang ${ }^{45}$ showed that the overall result is better if all major muscles that are involved are lengthened and/or trans- ferred during a single surgical procedure so that all lower extremity joints are balanced simultaneously. Therefore, singleevent multiple-level surgery is recommended and should be delayed until the gait is well established.

Objective three-dimensional gait analysis is achieved by means of kinematic, kinetic, and surface electromyographic studies in combination with careful clinical examination ${ }^{3,46,47}$. Gait analysis helps to identify muscles that are causing pathological motion patterns, provides better insight into the complexity of the motor problems, and makes possible the early detection of multiple-level problems as well as the recognition of inconsistent gait and the impact of the primary neurological disorder on gait. The findings of objective three-dimensional gait analysis may facilitate the use of alternative treatment modalities, such as botulinum toxin type A injections.

The objective of the present study was to evaluate, longitudinally, the possible effects of gait analysis and botulinum toxin type A treatment as a complement to nonoperative treatment in children with cerebral palsy and the effects of such a combination on the progression to surgical intervention. We hypothesized that, for children with cerebral palsy, the use of three-dimensional gait analysis and botulinum toxin type A injections, together with active motor training and suitable orthotic management, would delay the progression to surgical intervention and would reduce the prevalence of single-event orthopaedic surgery.

\section{Materials and Methods \\ Patients}

7 he present study was based on a retrospective review of 1 the charts of 2000 children with cerebral palsy who had been born between 1976 and 1994 and had been regularly treated at the outpatient clinic of our institution between 1976 and 2001. Between 1976 and 2001, there were two clear additions to the treatment strategy at our institution: (1) the addition of three-dimensional gait analysis in 1990 and (2) the use of botulinum toxin type A treatment in 1996. Therefore, the present study focused on three distinct periods, excluding the years during which the new treatment strategies were set up but not yet standardized. The first evaluation period focused on children who were seven to nine years of age from 1985 to 1989 , the second evaluation period focused on children who were seven to nine years of age from 1996 to 1997, and the third evaluation period focused on children who were seven to nine years of age from 2000 to 2001 . Children who were seven to nine years of age from 1990 to 1996 were not included in the study because the gait-analysis equipment and methodology were standardized at our institution during those years. By 1996, the gait-analysis procedure was well standardized and the multidisciplinary team had acquired the necessary expertise to use the additional information in the clinical decision-making process. Children who were seven to nine years of age from 1997 to 2000 were excluded from the study because botulinum toxin type A was only gradually being introduced as an available treatment option during those years. By focusing on children who were between seven and nine years 
The Journal of Bone \& JoInt Surgery - JBJS.org VOLUME 88-A · NUMBER 1 · JANUARY 2006
EfFects of Gait Assessment and Botulinum Toxin A on Musculoskeletal Surgery in Cerebral Palsy

TABLE I Characteristics of 424 Children with Cerebral Palsy

\begin{tabular}{|c|c|c|c|}
\hline Characteristics & Group $1(\mathrm{~N}=122)$ & Group $2(N=170)$ & Group $3(\mathrm{~N}=132)$ \\
\hline \multicolumn{4}{|l|}{ Diagnosis } \\
\hline Diplegia & $83(68 \%)$ & $95(56 \%)$ & $80(61 \%)$ \\
\hline Hemiplegia & $39(32 \%)$ & $75(44 \%)$ & $52(39 \%)$ \\
\hline $\begin{array}{l}\text { Mean age (and standard deviation) at time of } \\
\text { intake into the study }(y r)\end{array}$ & $4.4 \pm 2.3$ & $5.4 \pm 2.4$ & $3.3 \pm 1.6$ \\
\hline Mean duration of follow-up (and standard deviation) (yr) & $4.6 \pm 2.3$ & $3.6 \pm 2.4$ & $4.7 \pm 1.5$ \\
\hline \multicolumn{4}{|l|}{ Walking status at time of intake into the study } \\
\hline Independent & $64(52 \%)$ & $83(49 \%)$ & $57(43 \%)$ \\
\hline Limited assistance (support of 1 hand) & $29(24 \%)$ & $46(27 \%)$ & $42(32 \%)$ \\
\hline Substantial assistance (supported or with walking aids) & $26(21 \%)$ & $37(22 \%)$ & $28(21 \%)$ \\
\hline No independent walking & $3(2 \%)$ & $4(2 \%)$ & $5(4 \%)$ \\
\hline \multicolumn{4}{|l|}{ Use of daytime orthoses } \\
\hline Not used & $23(19 \%)$ & $41(24 \%)$ & $11(8 \%)$ \\
\hline Not frequently used ( $<50 \%$ of the day) & $34(28 \%)$ & $32(19 \%)$ & $24(18 \%)$ \\
\hline Intensively used ( $\geq 50 \%$ of the day) & $65(53 \%)$ & $97(57 \%)$ & $97(73 \%)$ \\
\hline \multicolumn{4}{|l|}{ Use of nighttime orthoses } \\
\hline Not used & $37(30 \%)$ & $46(27 \%)$ & $24(18 \%)$ \\
\hline Not frequently used ( $<25 \%$ of the night) & $30(25 \%)$ & $54(32 \%)$ & $49(37 \%)$ \\
\hline Intensively used ( $\geq 25 \%$ of the night) & $55(45 \%)$ & $70(41 \%)$ & $59(45 \%)$ \\
\hline \multicolumn{4}{|l|}{ Physiotherapy } \\
\hline No physiotherapy & $4(3 \%)$ & $8(5 \%)$ & $2(2 \%)$ \\
\hline Limited physiotherapy & $47(39 \%)$ & $56(33 \%)$ & $52(39 \%)$ \\
\hline Intensive physiotherapy ( $\geq 2$ sessions/week) & $71(58 \%)$ & $106(62 \%)$ & $78(59 \%)$ \\
\hline
\end{tabular}

of age from 2000 to 2001, we ensured that botulinum toxin type A treatment was well standardized and was available for all children at a young age.

Patients were included in the present study if they had (1) predominantly spastic hemiplegia or diplegia; (2) a minimum duration of follow-up of two years at the pediatric orthopaedic clinic; (3) a well-documented clinical history; (4) a history of appropriate physical and occupational therapy; (5) a history of daytime and nighttime use of orthoses; and (6) the capacity to walk at the time of the first clinical examination (at the time of intake into the study). The latter parameter was included to estimate the locomotor prognosis and to ensure that the children were relatively comparable with regard to motor capacity. At the time of the first clinical examination by the multidisciplinary team at our institution (defined as the age at the time of intake into the study), walking status was categorized as (1) independent, (2) limited assistance (walking with the support of one hand), (3) substantial assistance (walking with support or with walking aids), and (4) no independent walking (Table I). Some young children who were severely restricted on the basis of their walking status at the time of the first clinical evaluation started walking independently during the course of their motor development.

The progression to surgery was studied until the age of nine years because of the accepted advantages of delaying surgery until that age.
A total of 424 children met the inclusion criteria (Table I) and were divided into three groups on the basis of the previously mentioned evaluation periods. Patients in each group were managed according to the best-practice guidelines of pediatric orthopaedics at that time. All children were managed by the same multidisciplinary team, according to the same basic principles. Group 1 comprised 122 children who were seven to nine years of age from 1985 to 1989. They were managed according to best-practice guidelines of pediatric orthopaedics at that time, but without the input from threedimensional gait analysis and without botulinum toxin type A treatment. Group 2 comprised 170 children who were seven to nine years of age from 1996 to 1997. In addition to the use of the best-practice guidelines, important input on dynamic motor capacities was obtained with use of objective three-dimensional gait analysis. Gait analysis was planned at the first time the patient was clinically evaluated by the multidisciplinary team, but not before the age of four years, to identify the muscles and lever-arm dysfunctions that were causing pathological motion patterns. Gait analysis was repeated each time there was a need for more information regarding the complexity of the motor problems and before and after each operative or botulinum toxin type A treatment. Group 3 comprised 132 children who were seven to nine years of age from 2000 to 2001 . For this group, the treatment approach was similar to that for the second group, but 
The Journal of BOne \& JOINT SURgery • JBIS. ORG Volume 88-A · Number 1 · January 2006
EFFects of Gait Assessment and Botulinum Toxin A on Musculoskeletal Surgery in Cerebral Palsy botulinum toxin type A injections could be utilized. The first treatment with botulinum toxin type A usually was planned for when the patient was between the ages of two and four years. It should be noted that botulinum toxin type A treatment was not an inclusion criterion for Group 3 but rather was available as a treatment option in Group 3. Botulinum toxin type A treatment in Group 3 was administered only when it was indicated by an insufficient response to a conservative approach, such as intolerance of day and night splinting, development of fixed-muscle contractures, a decrease in functionality, and no further improvement following physiotherapy.

\section{Outcome Parameters}

Outcome parameters included the age of the patient at the time of each orthopaedic surgical intervention, the type of surgery (one level or multiple levels), the procedures performed (correction of soft-tissue abnormalities and/or osseous deformities), the total number of surgical interventions, the age at the time of each gait analysis, and the age at the time of each treatment with botulinum toxin type A. The diagnosis, the intensity of physical therapy, the frequency of use of daytime and nighttime orthoses, and the ability to walk at the time of the first clinical examination were defined as covariates for each patient.

\section{Operative Procedures}

Orthopaedic surgery was indicated when secondary problems, including structural muscle contractures, osseous deformities, and lever-arm dysfunction, largely limited motor function as determined on the basis of observation and clinical examination and, for Groups 2 and 3, three-dimensional gait analysis ${ }^{48,49}$. In the present study, soft-tissue surgery included lengthening of the psoas ${ }^{50,51}$, adductor longus (and brevis) (2,53 $^{52}$ and medial hamstrings ${ }^{54,55}$; transfer of the rectus femoris to either the gracilis or semitendinosus muscles ${ }^{56,57}$; procedures involving the gastrocnemius $^{58}$, including Achilles tendon lengthening ${ }^{59}$; peroneal muscle lengthening ${ }^{60}$; tibialis posterior lengthening ${ }^{61}$ or split transfer ${ }^{62}$; tibialis anterior split transfer ${ }^{63}$; and flexor hallucis longus and abductor hallucis lengthening ${ }^{64}$. Osseous deformities were corrected by means of acetabular procedures (acetabuloplasty $)^{65-68}$, proximal femoral varus derotation osteotomy ${ }^{69}$, distal tibial derotation osteotomy ${ }^{70}$, and foot stabilization surgery (calcaneus lengthening combined with medial soft-tissue shortening, or subtalar arthrodesis) ${ }^{71,72}$.

Three-dimensional analysis of gait in Groups 2 and 3 and clinical examination by the multidisciplinary team were used to define the treatment goals, to describe the pattern of motion of each joint, and to identify the muscles and osseous deformities that caused pathological patterns, according to which treatment could be modified ${ }^{36}$. Included in the full three-dimensional gait analysis were kinematic and kinetic data obtained with use of a six-camera VICON motion-capture system (VICON Motion Systems; Lake Forest, California) and two AMTI force-plates (Advanced Mechanical Technology, Watertown, Massachusetts), combined with surface electromyography (sixteen-channel L-Lab EMG system, The Neth- erlands) of seven lower-extremity muscles on both limbs. The follow-up gait analysis facilitated an objective evaluation of outcomes, which helped to refine the overall treatment strategy for each child. By carefully evaluating the treatment outcome, we were able to track the child's development of new motor abilities. Generating a new baseline of the patient's gait pattern also allowed for the development of new recommendations aimed at preserving the therapeutic benefits.

Botulinum toxin type A treatment was administered only as a result of an insufficient response to nonoperative treatment (such as an intolerance to orthotics, the development of fixedmuscle contractures, a decrease in functionality, and a lack of further improvement in response to physiotherapy) and was applied according to the integrated approach described by us in a previous study $y^{29}$. A dilution of 100 units (U) botulinum toxin type A in $2 \mathrm{~mL}$ of saline solution was used. Each selected muscle was injected at multiple sites, to a maximum of $50 \mathrm{U}$ per site, while the child was sedated with mask anesthesia. The dosage at the time of the study (calculated according to the number of selected muscles and total body weight) ranged from 14 to $31 \mathrm{U} / \mathrm{kg}$ body weight for children with diplegia and from 6 to $23.5 \mathrm{U} / \mathrm{kg}$ body weight for children with hemiplegia ${ }^{29,36}$. For each treated lower extremity, one to six muscles were injected during one session. The muscles that were most frequently targeted for injection were the gastrocnemius and the medial hamstrings; other targeted muscles included the soleus, the tibialis posterior, the adductors, and the iliopsoas. Botulinum toxin type A injections were combined with conservative treatment options (physiotherapy, orthotic management, and stretching casts) as needed.

\section{Statistical Methods}

Statistical analysis was performed under the supervision of the university's Department of Public Health and Biostatistical Centre. Factors that could influence the progression to surgery were compared among the three groups with use of the chisquare test. The frequency distribution for the first session of surgery at different ages for the three study groups was first analyzed with the chi-square test. Similar frequency distributions for the second and third sessions of surgical intervention also were calculated at different ages and for different types of surgery. With the application of a Bonferroni correction to define the overall type-I error for five chi-square tests, an appropriate level of significance was defined as $\mathrm{p}<0.01$. Survival analysis was then used to evaluate the period leading up to the first surgery, taking into account the dependence of different covariates on the risk of surgery. The covariates were defined as the diagnosis, the intensity of physical therapy, the frequency of use of daytime orthoses, the frequency of use of nighttime orthoses, and the walking status at the time of the first clinical examination. The time of the first contact in the outpatient clinic was considered to be the time of origin in the study, and estimations of survivor functions were calculated with use of the Kaplan-Meier method. The log-rank test was used to assess the significance of the differences in obtained survivor functions, taking into account the censored observations and considering $1 \%$ as the level of significance. 
The JOURnAL of BONE \& JOINT SURGERY • JBJS.ORG VOLUme 88-A · NUmber 1 · JANUARY 2006
EfFects of Gait Assessment and Botulinum Toxin A on Musculoskeletal Surgery in Cerebral Palsy

\section{Results}

The inclusion criteria were met by 424 patients (Table I). 1 The mean age (and standard deviation) at the time of the initial evaluation was $4.4 \pm 2.3$ years for Group $1,5.4 \pm 2.4$ years for Group 2, and 3.3 \pm 1.6 years for Group 3. Because of the strict inclusion criteria, all patients in the present retrospective study had to have had well-documented follow-up at the pediatric orthopaedic clinic until the age of seven years or older; therefore, no patient was lost to follow-up before the age of seven years. All children in Groups 1 and 2 were followed until the age of nine years; forty (30\%) of the 132 children in Group 3 had not reached the age of nine years at the time of data collection. The mean duration of follow-up for these children was $4.7 \pm 1.5$ years. The lack of follow-up in the last two years (censored observations) did not bias the results because it was taken into account in the frequency distributions (Fig. 1), in the Kaplan-Meier survival analysis, and in the log-rank test (Fig. 2, Tables II and III).

The three groups showed similar distributions in terms of baseline characteristics (Table I), including the topographic classification and the ability to walk at the time of the first clinical evaluation. Botulinum toxin type A injections, which were only applied as a result of an insufficient response to a conservative approach, were administered to 115 (87\%) of the 132 patients in Group 3 before the age of seven years. Except for the use of daytime orthoses, the distribution of physical therapy and orthotic conditions did not differ among the three groups. Intensive use of daytime orthoses during followup was most often seen in Group 3 ( $\mathrm{p}<0.002)$ (Table I).

All children in Groups 1 and 2 were followed until the age of nine years. In Group 3, sixteen of the 132 children had not reached the age of eight years and forty of the 132 children had

\begin{tabular}{|cccc|}
\hline \multicolumn{4}{|c|}{ TABLE II Percentile Estimates for Median Survival Times } \\
Before First Surgical Session
\end{tabular}

\begin{tabular}{|c|c|c|c|}
\hline Walking Status & $\begin{array}{l}\text { Group 1 } \\
(\mathrm{N}=122)\end{array}$ & $\begin{array}{l}\text { Group } 2 \\
(\mathrm{~N}=170)\end{array}$ & $\begin{array}{l}\text { Group } 3 \\
(\mathrm{~N}=92)\end{array}$ \\
\hline Independent & $53 \%$ & $63 \%$ & $100 \%$ \\
\hline Limited assistance & $21 \%$ & $59 \%$ & $80 \%$ \\
\hline $\begin{array}{l}\text { Substantial assistance } \\
\text { or no independent walking }\end{array}$ & $21 \%$ & $47 \%$ & $80 \%$ \\
\hline
\end{tabular}

not reached the age of nine years at the time of data collection. By the age of seven years, sixty-four (52\%) of the 122 patients in Group 1 had undergone at least one surgical procedure, compared with forty-six (27\%) of the 170 patients in Group 2 and thirteen $(10 \%)$ of the 132 patients in Group 3. By the age of eight years, seventy-three (60\%) of the 122 patients in Group 1 had undergone at least one surgical procedure, compared with fifty-two $(31 \%)$ of the 170 patients in Group 2 and fourteen $(12 \%)$ of 116 patients in Group 3. By the age of nine years, seventy-nine $(65 \%)$ of the 122 patients in Group 1 had under-

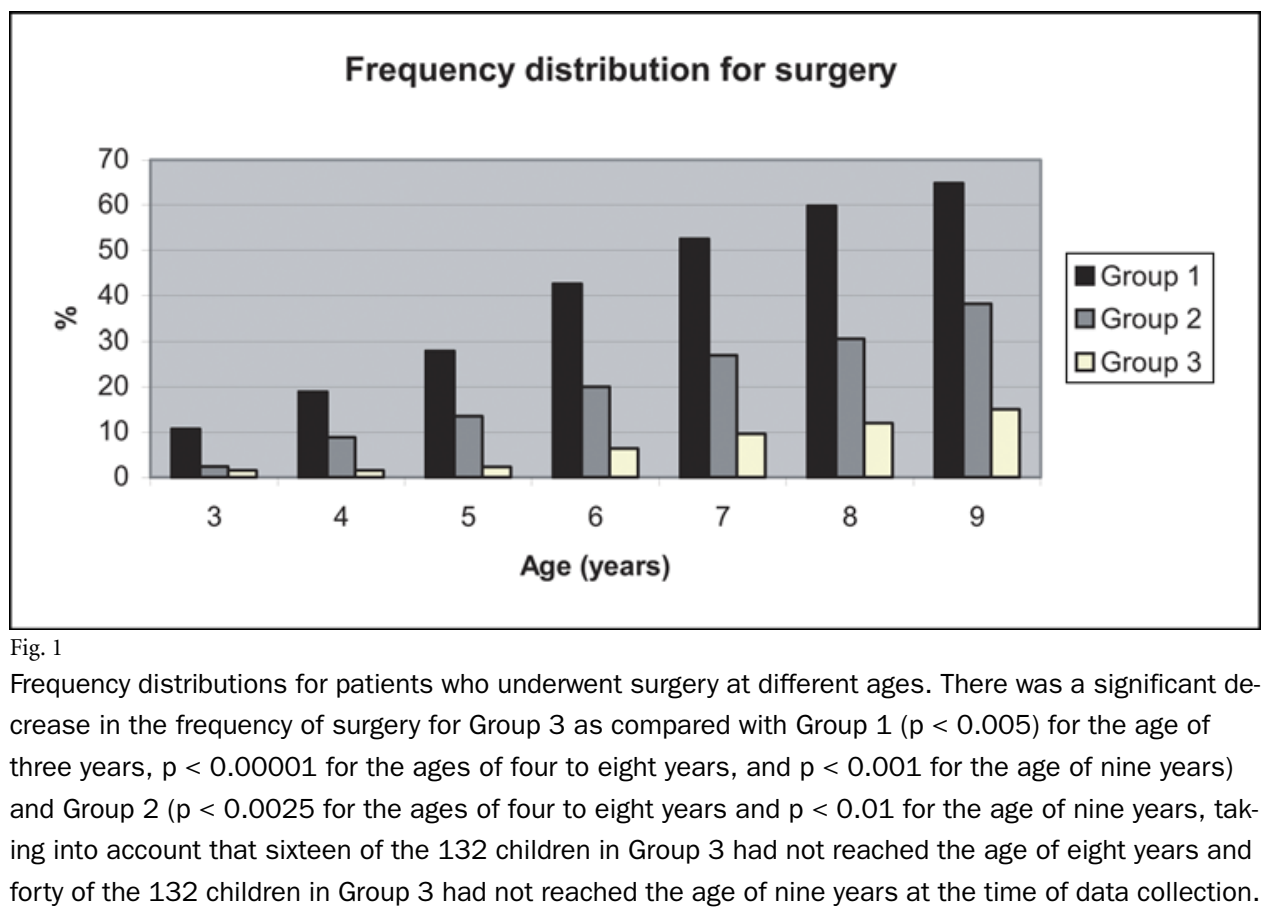




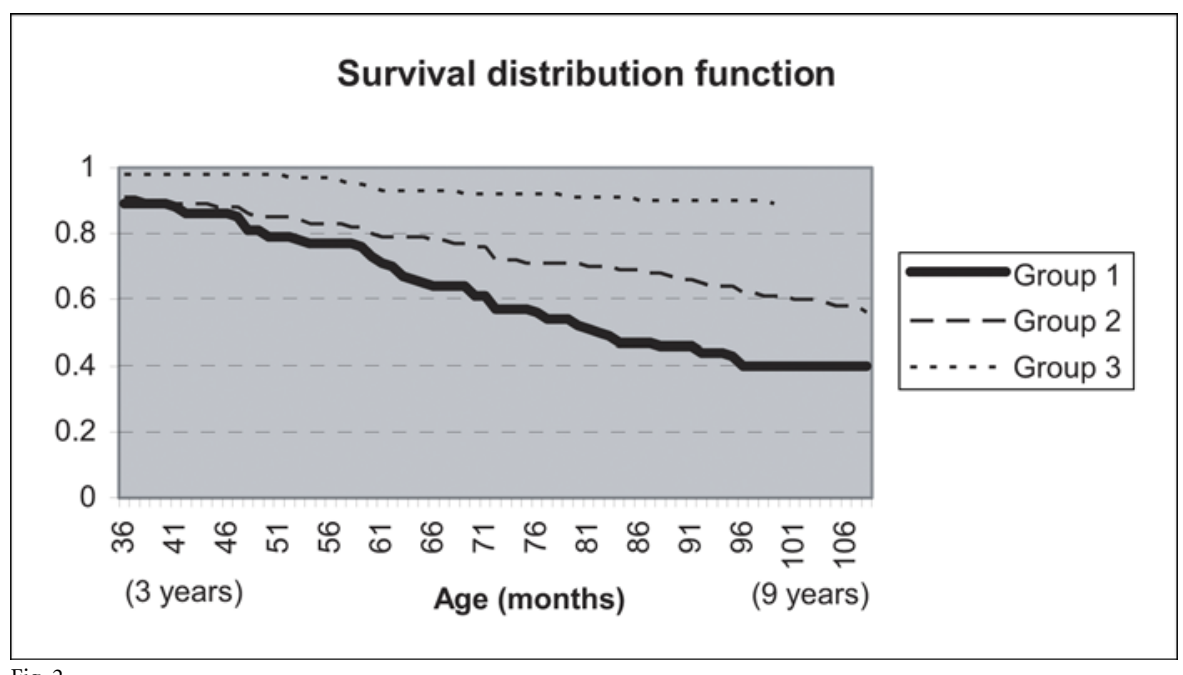

Fig. 2

Kaplan-Meier survival curves, with the occurrence of the first surgical procedure as the end point, for all 424 patients. The survival rate was significantly different among the three groups for the ages of three to nine years $(p<0.0001$, log-rank test). The standard error of the KaplanMeier estimates was 0.48 for Group 1, 0.71 for Group 2, and 0.11 for Group 3.

gone at least one surgical procedure, compared with sixty-five (38\%) of the 170 patients in Group 2 and fourteen (15\%) of ninety-two patients in Group 3. The difference between the prevalence of surgery in Groups 1 and 2 was significant at seven, eight, and nine years of age $(\mathrm{p}<0.00001$, chi-square test). There was a significant decrease in the frequency of surgery in Group 3 as compared with Group 1 ( $\mathrm{p}<0.005$ for the age of three years, $\mathrm{p}<0.0001$ for the ages of four to eight years, and $\mathrm{p}<$ 0.001 for the age of nine years) and Group 2 ( $p<0.0025$ for the ages of four to eight years, and $p<0.01$ for the age of nine years). The rate of survival, with the occurrence of the first surgical procedure as the end point, was significantly different among the three groups for the ages of three to nine years ( $\mathrm{p}<$ 0.0001 , log-rank test) (Fig. 2). The median for survival was found to be 6.8 years for Group 1, 9.8 years for Group 2, and was never reached for Group 3 (Table II).

Survival analysis revealed differences among the four walking-status categories with regard to the risk of surgery (Table I). Although the baseline distribution with regard to walking status was similar among the three treatment groups, evaluation of the impact of covariates on the risk of surgery revealed a significant influence of walking ability at the time of the initial clinical evaluation. The survival estimates at the age of nine years are given in Table III. By the age of nine years, the proportion of patients who had not had surgery was always higher in Group 2 as compared with Group 1. These differences between Groups 1 and 2 were most pronounced for the children who walked with limited assistance (59\% [101 of 170] for Group 2, compared with 21\% [twenty-six of 122] for Group 1) and for the children who walked only with substantial assistance or who could not walk independently (47\% [eighty of 170] for Group 2 , compared with $21 \%$ [twenty-six of 122] for Group 1) at the time of the initial clinical evaluation (at a mean age of 4.4 years for Group 1 and of 5.4 years for Group 2). In Group 3, progression to surgery was never seen among the children who were able to walk at the time of the initial clinical evaluation (mean age, 3.3 years). The survival rate for Group 3 was $80 \%$ (106 of 132), with surgery being performed only for children who walked with limited assistance, and children who walked with substantial assistance, or children who could not walk independently at the time of the initial evaluation.

Analysis of the frequency distributions for the second surgical intervention by the age of seven years revealed that eleven $(21 \%)$ of fifty-two children in Group 1 needed two surgery sessions, six (14\%) of forty-three children in Group 2 needed two surgery sessions, and none of the children in Group 3 needed more than one surgery session. Before the age of thirteen years, fifty-five (45\%) of the 122 children in Group 1 and twenty-four (41\%) of fifty-nine children in Group 2 needed a second surgical procedure. No conclusions could be made about the children in Group 3 because they had not reached the age of thirteen years by the time of data collection. By the age of nine years, none of the twelve children in Group 3 who had had one session of surgery needed a second session of surgery, compared with nineteen $(26 \%)$ of the seventy-four children in Group 1 and fourteen $(21 \%)$ of the sixty-eight children in Group 2.

The frequency of single surgical interventions (Achilles tendon lengthening) as well as multiple-level interventions (other soft-tissue surgery with or without correction of osseous deformities) during the first session of surgery is presented in Figure 3. By the age of seven years, forty-seven (39\%) of the 122 patients in Group 1, thirty-four (20\%) of the 170 patients in Group 2, and three (3\%) of 116 patients in Group 3 underwent Achilles tendon lengthening, whereas multiple-level surgery was performed for seventeen $(14 \%)$ of 
The JOURnAL OF BONE \& JOINT SURgEry • JBJS.ORG VOLUME 88-A · NUMBER 1 · JANUARY 2006
Effects of Gait Assessment and Botulinum Toxin A on Musculoskeletal Surgery in Cerebral Palsy the 122 patients in Group 1, nineteen (11\%) of the 170 patients in Group 2, and eight (7\%) of 116 patients in Group 3.

\section{Discussion}

ur intermediate-term results suggest that a multiple-level treatment approach involving physical and occupational therapy, orthotic treatment, and botulinum toxin type A treatment should start at a young age, when gait patterns and motor capacities are not yet well established. Our results suggest that the treatment of primary motor problems with botulinum toxin type A can delay the development of secondary problems until at least the age of nine years.

The differences in the risk of surgery between Group 1 and Group 2 became clear at the age of approximately six years (Fig. 1). The survival rate at the age of twelve years, with the first surgical procedure as the end point, was $27 \%$ for Group 1 and $42 \%$ for Group 2. For these children, the use of three-dimensional gait analysis for Group 2 was the only difference in follow-up data. Gait analysis was planned each time there was a need for more information about motor problems to define the optimal treatment plan as well as before and after each nonoperative or operative intervention. The children in Group 3 will reach the mean age of twelve years in 2006. The survival rate at the age of seven years, with the first surgical procedure as the end point, improved from $48 \%$ for Group 1 to $69 \%$ for Group 2 and to $90 \%$ for Group 3 (Fig. 2). Before the age of thirteen years, $45 \%$ (fifty-five) of the 122 children in Group 1 and 41\% (twenty-four) of fifty-nine children in Group 2 needed a second session of surgery. Although no conclusions could be made about the follow-up of children in Group 3 until the age of thirteen years, none of the ninety-two children in Group 3 who reached the age of nine years needed a second session of surgery. The improved motor function after the initial surgical procedure could not be maintained. Therefore, the risk-benefit ratio of surgery ${ }^{38}$ also should be considered, as should the physical, social, and psychological impact of repeated surgery ${ }^{73}$.

Although the aim of the multiple-level treatment approach was to lengthen and/or transfer all major muscles that were involved and to correct all osseous deformities and leverarm dysfunction during the course of a single surgical procedure, multiple-level involvement was not always properly recognized at the time of the initial surgery session for the children in Group 1 because of a lack of objective threedimensional gait analysis. Therefore, Achilles tendon lengthening at a young age was a common procedure for these children.

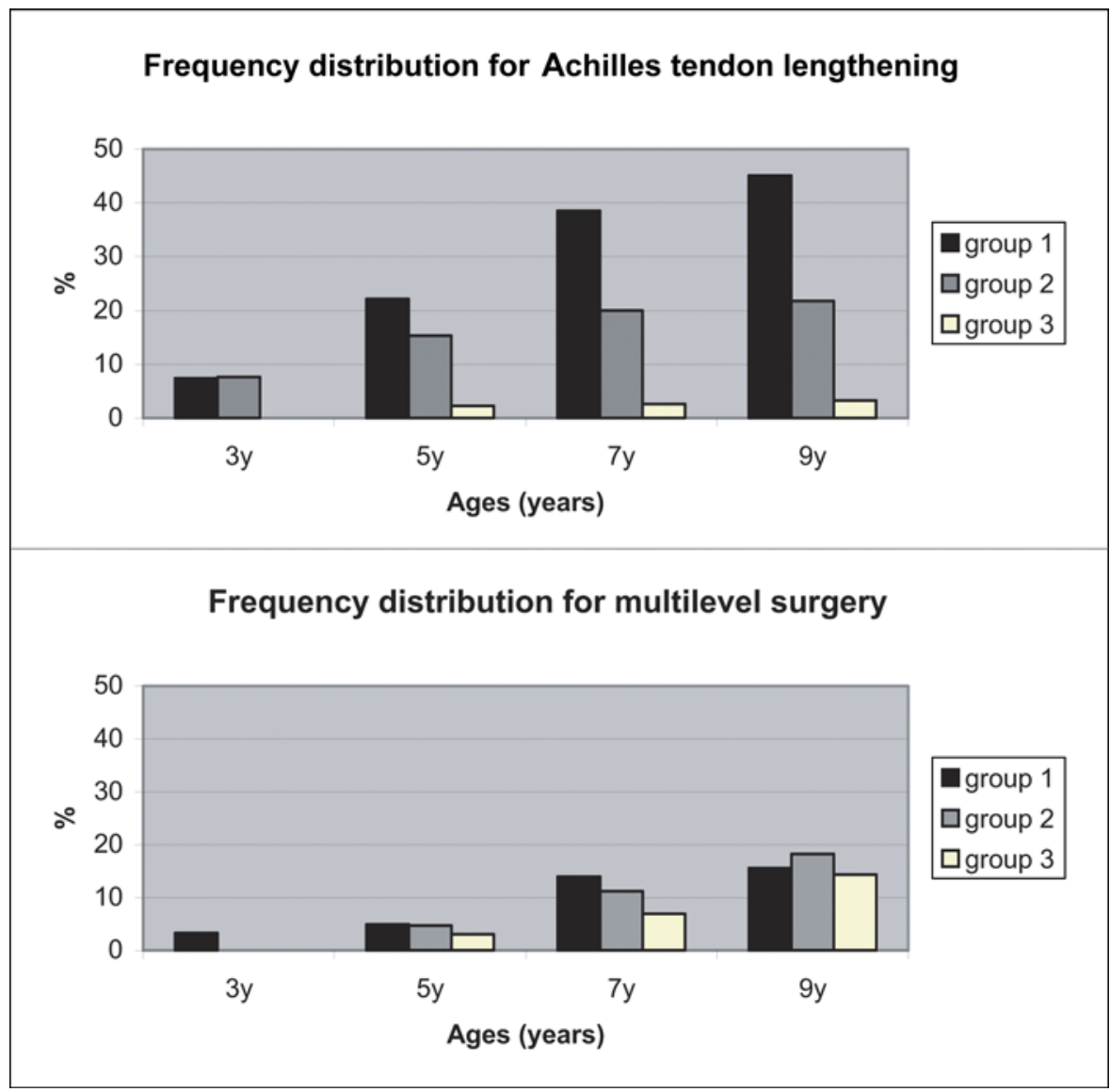

Fig. 3

Frequency distributions for patients who underwent single-level surgery (Achilles tendon lengthening) and multiple-level surgery at different ages. 
THE JOURNAL OF BONE \& JOINT SURGERY • JBJS.ORG Volume 88-A · Number $1 \cdot$ January 2006
EFFects of Gait Assessment and Botulinum Toxin A on Musculoskeletal Surgery in Cerebral Palsy
As previously discussed, there are clear advantages of delaying surgery until the age of eight years or older, by which time the gait is well established ${ }^{3,9,10,44}$. Koman et al. ${ }^{43}$ evaluated the effect of single-level botulinum toxin type A treatment on the need for Achilles tendon lengthening surgery after a mean duration of follow-up of 3.4 years (range, 0.4 to 6.5 years). The study demonstrated a 3.8 -year delay in surgical treatment and an older age at which Achilles tendon lengthening was performed in comparison with the timing of surgery as cited in other studies ${ }^{7,9}$. We are not aware of any long-term studies on the outcome of multiple-level treatment with botulinum toxin type A. Bakheit et al. ${ }^{74}$, in a study of 1594 botulinum toxin type A injections in children with muscle spasticity, concluded that multiple-level injections resulted in a better overall response than single-level injections did. Galli et al. ${ }^{75}$ and Mall et al. ${ }^{76}$ also emphasized the need for multiple-level injections. However, it was surprising that, in the majority of the reported studies, application of botulinum toxin type A was limited to isolated treatment of spasticity of the gastrocnemius muscle. However, as discussed previously, most previous investigators have agreed with the principle of multiple-level treatment during one $\operatorname{session}^{3,745,77}$. We developed appropriate techniques to apply the multiple-level botulinum toxin type A approach safely ${ }^{29}$; however, the inter-relationship of botulinum toxin type A treatment with the general motor development of the child with cerebral palsy has not been examined in large cohorts.

The present study revealed the first intermediate to long-term effects of serial multiple-level botulinum toxin type A injections, combined with nonoperative treatment, on longitudinal muscle growth. It is important to note that no important adverse effects of the combined botulinum toxin type A and casting treatments were noted at the doses used and that only minor complications were seen. Unintended effects or side effects (incontinence and constipation) were noted in $<5 \%$ of the patients (in association with four of ninety-one treatments ${ }^{29,36}$.

The three groups had similar distributions of known factors (except for the use of daytime orthoses) that could influence motor development and progression to surgery. The same orthotic management was applied in all three groups, which was always the maximum of tolerated daytime and nighttime use. However, daytime orthoses were more intensively used in Group 3 as compared with Groups 1 and 2 , suggesting that botulinum toxin type A may facilitate the use of orthoses, as evidenced by the results of previous studies $^{29,36,39}$. For Group 3, there were no follow-up data for forty of 132 patients from the ages of seven to nine years because these children had not reached the age of nine years at the time of data collection. Although the survival analysis took the censored observations into account, care should be given to conclusions based on the results for the children in Group 3 after the age of seven years.

The retrospective nature of the present study limits the interpretation of the results, and the possibility of bias in favor of a delay of surgery should be considered. However, all of the children in the present study were evaluated and managed by the same multidisciplinary team according to the best practice guidelines of orthopaedic treatment. The treatment plan for each child was defined in the multidisciplinary outpatient clinic. The advantages of the multidisciplinary approach and single-event, multiple-level surgery were generally accepted at the onset of this retrospective study and had been applied by the senior member of this research team (G.F.) since 1972. The treatment philosophy per se did not change over the course of this retrospective study. Rather, the improved understanding and treatment of cerebral palsyrelated primary problems in children helped to optimize the use of available treatment options. Although this treatment strategy might not be generally accepted by all clinicians, the presented strategy was stable throughout the course of the study.

In the present study, there also were small differences among the three groups with regard to the age of first contact. Children in Group 3, in particular, were younger at the time of the first clinical evaluation, which may have predisposed them to a better locomotor prognosis. However, these children also demonstrated a more severely restricted walking ability at the time of the initial evaluation (Table I). It is well known that walking ability is linked to the severity of pathology in patients with cerebral palsy ${ }^{1,4,78-82}$, and our survival analysis confirmed that more severely restricted walking ability at a young age significantly delayed the time to surgery. Therefore, it cannot be stated with certainty that a young age at the time of the first clinical evaluation was an advantage for the children in Group 3 as they also had more severely restricted walking ability at a younger age as compared with the children in Groups 1 and 2. This finding suggested that the severity of pathology in Group 3 might have been the same as, but was certainly not better than, that in Groups 1 and 2.

The results of the present intermediate-term study revealed that the children with the least walking ability (those who could walk only with substantial support or who could not walk independently) at the time of the initial evaluation progressed to surgery more frequently than did the children who were able to walk at a young age. However, the proportion of these children in Group 3 who had not had surgery by the age of nine years was lower than the proportion of the more functional children who were able to walk in Groups 1 and 2. Taken together, these data suggest that the locomotor prognosis of the children in Group 3 who were not able to walk was no better than that of children in Groups 1 and 2, despite the younger age of these children at the time of the first clinical evaluation. Additional study will be needed to establish the influence of young age as compared with that of walking status on locomotor prognosis.

Future data analysis in this retrospective study will focus on the general functional condition of the children who received botulinum toxin type A treatment at the age of six to ten years as compared with a control group. The functional outcome, evaluated with use of gait analysis, is beyond the scope of this study but will be analyzed in the near future. 
The Journal of Bone \& JoInt SURGERy · JBJS.ORG Volume 88-A · Number $1 \cdot$ January 2006
Effects of Gait Assessment and Botulinum Toxin A on Musculoskeletal Surgery in Cerebral Palsy
Guy Molenaers, MD, PhD

Guy Fabry, MD, PhD

Department of Pediatric Orthopaedics, University Hospital Pellenberg, Weligerveld 1, 3212 Pellenberg, Belgium. E-mail address for G. Molenaers: guy.molenaers@uz.kuleuven.ac.be

Kaat Desloovere, $\mathrm{PhD}$

Gait Analysis Laboratory CERM and Department of Rehabilitation Sciences, University Hospital Pellenberg and Katholieke Universiteit Leuven, Weligerveld 1, 3212 Pellenberg, Belgium

Paul De Cock, MD, PhD

Department of Neuro-pediatrics, University Hospital of Leuven, Gasthuisberg, Herestraat 1, 3000 Leuven, Belgium
In support of their research for or preparation of this manuscript, one or more of the authors received grants or outside funding from Allergan, Inc., Irvine, California. None of the authors received payments or other benefits or a commitment or agreement to provide such benefits from a commercial entity. No commercial entity paid or directed, or agreed to pay or direct, any benefits to any research fund, foundation, educational institution, or other charitable or nonprofit organization with which the authors are affiliated or associated.

doi:10.2106/JBJS.C.01497

\section{References}

1. Crothers B, Paine RS. The natural history of cerebral palsy. Cambridge: Harvard University Press; 1959.

2. Bleck EE. Orthopaedic management in cerebral palsy. London: MacKeith Press; 1987.

3. Gage JR. Gait analysis in cerebral palsy. London: MacKeith Press; 1991.

4. Connolly KJ, Forssberg $\mathrm{H}$, editors. The neurophysiology and neuropsychology of motor development. London: MacKeith Press; 1997.

5. Lance JW. Pathophysiology of spasticity and clinical experience with baclofen. In: Feldman RG, Young RR, Koella WP, editors. Spasticity, disordered motor control. Chicago: Year Book Medical; 1980. p 328-34.

6. Lin JP, Brown JK, Walsh EG. Continuum of reflex excitability in hemiplegia: influence of muscle length and muscular transformation after heel-cord lengthening and immobilization on the pathophysiology of spasticity and clonus. Dev Med Child Neurol. 1999;41:534-48.

7. Norlin R, Tkaczuk H. One-session surgery for correction of lower extremity deformities in children with cerebral palsy. J Pediatr Orthop. 1985;5:208-11.

8. Rang M, Silver R, de la Garza J. Cerebral palsy. In: Lovell WW, Winter RB, editors. Pediatric orthopaedics. 2nd ed. Philadelphia: Lippincott; 1986. p 345-96.

9. Borton DC, Walker K, Pirpiris M, Nattrass GR, Graham HK. Isolated calf lengthening in cerebral palsy. Outcome analysis of risk factors. J Bone Joint Surg Br. 2001;83:364-70.

10. Fabry G, Liu XC, Molenaers G. Gait pattern in patients with spastic diplegic ce rebral palsy who underwent staged operations. J Pediatr Orthop B. 1999;8:33-8.

11. Ounpuu S, Gage JR, Davis RB. Three-dimensional lower extremity joint kinetics in normal pediatric gait. J Pediatr Orthop. 1991;11:341-9.

12. Sutherland DH, Olshen RA, Biden EN, Wyatt MP. The development of mature walking. Oxford: MacKeith Press; 1988.

13. Norlin R, Odenrick $P$, Sandlund B. Development of gait in the normal child. J Pediatr Orthop. 1981;1:261-6.

14. Stansfield BW, Hillman SJ, Hazlewood ME, Lawson AA, Mann AM, Loudon IR, Robb JE. Sagittal joint kinematics, moments, and powers are predominantly characterized by speed of progression, not age, in normal children. J Pediatr Orthop. 2001;21:403-11.

15. Norlin R, Odenrick P. Development of gait in spastic children with cerebral palsy. J Pediatr Orthop. 1986;6:674-80

16. Dodd KJ, Taylor NF, Graham HK. A randomized clinical trial of strength training in young people with cerebral palsy. Dev Med Child Neurol. 2003;45:652-7.

17. Brown GT, Burns SA. The efficacy of neurodevelopmental treatment in paediatrics: a systematic review. Br J Occup Ther. 2001;64:235-44.

18. Knox V, Evans AL. Evaluation of the functional effects of a course of Bobath therapy in children with cerebral palsy: a preliminary study. Dev Med Child Neurol. 2002;44:447-60.

19. Butler C, Darrah J. Effects of neurodevelopmental treatment (NDT) for cerebral palsy: an AACPDM evidence report. Dev Med Child Neurol. 2001;43:778-90

20. Bower E, Michell D, Burnett M, Campbell MJ, McLellan DL. Randomized controlled trial of physiotherapy in 56 children with cerebral palsy followed for 18 months. Dev Med Child Neurol. 2001;43:4-15.

21. Trahan J, Malouin F. Intermittent intensive physiotherapy in children with cerebral palsy: a pilot study. Dev Med Child Neurol. 2002;44:233-9.
22. Bertoti DB. Effect of short leg casting on ambulation in children with cerebral palsy. Phys Ther. 1986;66:1522-9.

23. Watt J, Sims D, Harckham F, Schmidt L, McMillan A, Hamilton J. A prospective study of inhibitive casting as an adjunct to physiotherapy for cerebral-palsied children. Dev Med Child Neurol. 1986;28:480-8.

24. Hinderer KA, Harris SR, Purdy AH, Chew DE, Staheli LT, McLaughlin JF, Jaffe KM. Effects of 'tone-reducing' vs. standard plaster-casts on gait improvement of children with cerebral palsy. Dev Med Child Neurol. 1988;30:370-7.

25. Hinkle DE, Wiersma W, Jurs SG. Applied statistics for the behavioral sciences. 4th ed. Boston: Houghton Mifflin; 1998.

26. DeLuca PA. The musculoskeletal management of children with cerebral palsy. Pediatr Clin North Am. 1996;43:1135-50.

27. Brouwer B, Wheeldon RK, Stradiotto-Parker N, Allum J. Reflex excitability and isometric force production in cerebral palsy: the effect of serial casting. Dev Med Child Neurol. 1998;40:168-75.

28. Graham HK. Botulinum toxin type A management of spasticity in the context of orthopaedic surgery for children with spastic cerebral palsy. Eur J Neurol. 2001;8 Suppl 5:30-9

29. Molenaers G, Desloovere K, Eyssen M, De Cat J, Jonkers I, De Cock P. Botulinum toxin type A treatment of cerebral palsy: an integrated approach. Eur J Neurol. 1999;6:S51-7.

30. Albright AL, Neville B. Pharmacological management of spasticity. In: Albright AL, Neville B, editors. The management of spasticity associated with the cerebral palsies in children and adolescents. Secaucus, New Jersey: Churchill Communications; 2000. p 121-33.

31. Goldstein M, Harper DC. Management of cerebral palsy: equinus gait. Dev Med Child Neurol. 2001;43:563-9.

32. Koman LA, Mooney JF 3rd, Smith B, Goodman A, Mulvaney T. Management of cerebral palsy with botulinum-A toxin: preliminary investigation. J Pediatr Orthop. 1993;13:489-95

33. Sutherland DH, Kaufman KR, Wyatt MP, Chambers HG, Mubarak SJ. Doubleblind study of botulinum A toxin injections into the gastrocnemius muscle in patients with cerebral palsy. Gait Posture. 1999;10:1-9.

34. Flett PJ, Stern LM, Waddy H, Connell TM, Seeger JD, Gibson SK. Botulinum toxin A versus fixed cast stretching for dynamic calf tightness in cerebral palsy. J Paediatr Child Health. 1999;35:71-7.

35. Koman LA, Mooney JF 3rd, Smith BP, Walker F, Leon JM. Botulinum toxin type A neuromuscular blockade in the treatment of lower extremity spasticity in cerebral palsy: a randomized, double-blind, placebo-controlled trial. BOTOX study group. J Pediatr Orthop. 2000;20:108-15.

36. Desloovere K, Molenaers G, Jonkers I, De Cat J, De Borre L, Nijs J, Eyssen M, Pauwels $P$, De Cock P. A randomized study of combined botulinum toxin type $A$ and casting in the ambulant child with cerebral palsy using objective outcome measures. Eur J Neurol. 2001;8 Suppl 5:75-87.

37. Love SC, Valentine JP, Blair EM, Price CJ, Cole JH, Chauvel PJ. The effect of botulinum toxin type $A$ on the functional ability of the child with spastic hemiplegia a randomized controlled trial. Eur J Neurol. 2001;8 Suppl 5:50-8.

38. Molenaers G, Desloovere K, De Cat J, Jonkers I, De Borre L, Pauwels P, Nijs J, Fabry G, De Cock P. Single event multilevel botulinum toxin type A treatment and surgery: similarities and differences. Eur J Neurol. 2001;8 Suppl 5:88-97. 
The Journal of Bone \& JoINT SURGERY · JBJS.org Volume 88-A · Number $1 \cdot$ January 2006
EfFects of Gait Assessment and Botulinum Toxin A on Musculoskeletal Surgery in Cerebral Palsy
39. Graham HK, Aoki KR, Autti-Rämo I, Boyd RN, Delgado MR, Gaebler-Spira DJ, Gormley ME, Guyer BM, Heinen F, Holton AF, Matthews D, Molenaers G, Motta F, Garcia Ruiz PJ, Wissel J. Recommendations for the use of botulinum toxin type A in the management of cerebral palsy. Gait Posture. 2000;11:67-79.

40. Preiss RA, Condie DN, Rowley DI, Graham HK. The effects of botulinum toxin (BTX-A) on spasticity of the lower limb and on gait in cerebral palsy. J Bone Joint Surg Br. 2003;85:943-8.

41. Boyd R, Graham HK. Botulinum toxin $A$ in the management of children with cerebral palsy. Eur J Neurol. 1997;4:S15-22.

42. Wissel J, Heinen F, Schenkel A, Doll B, Ebersbach G, Müller J, Poewe W. Botulinum toxin $A$ in the management of spastic gait disorders in children and young adults with cerebral palsy: a randomized, double-blind study of "high-dose" versus "low-dose" treatment. Neuropediatrics. 1999:30:120-4.

43. Koman LA, Smith BP, Tingey CT, Mooney JF, Slone S, Naughton MJ. The effect of botulinum toxin type $A$ injections on the natural history of equinus foot deformity in pediatric cerebral palsy patients. Eur J Neurol. 1999;6:S19-22.

44. Delp SL, Arnold AS, Piazza SJ. Graphics-based modeling and analysis of gait abnormalities. Biomed Mater Eng. 1998;8:227-40.

45. Wenger DR, Rang M. The art and practice of children's orthopaedics. New York: Raven Press; 1993.

46. Sutherland DH. The evolution of clinical gait analysis part 1: kinesiological EMG. Gait Posture. 2001;14:61-70.

47. Sutherland DH. The evolution of clinical gait analysis. Part II kinematics. Gait Posture. 2002;16:159-79.

48. Renshaw TS. Cerebral palsy. In: Morrissy RT, Weinstein SL, editors. Lovell and Winter's pediatric orthopaedics. 5th ed. Philadelphia: Lippincott Williams and Wilkins; 2001. p 564-99.

49. Herring JA, editor. Tachdjian's pediatric orthopedics. 3rd ed. Philadelphia: Saunders; 2002.

50. Sutherland DH, Zilberfarb JL, Kaufman KR, Wyatt MP, Chambers HG. Psoas release at the pelvic brim in ambulatory patients with cerebral palsy: operative technique and functional outcome. J Pediatr Orthop. 1997:17:563-70.

51. Matsuo $\mathrm{T}$, Hara $\mathrm{H}$, Tada S. Selective lengthening of the psoas and rectus femoris and preservation of the iliacus for flexion deformity of the hip in cerebra palsy patients. J Pediatr Orthop. 1987;7:690-8.

52. Matsuo T, Tada S, Hajime T. Insufficiency of the hip adductor after anterior obturator neurectomy in 42 children with cerebral palsy. J Pediatr Orthop. 1986; 6:686-92.

53. Reimers J, Poulsen S. Adductor transfer versus tenotomy for stability of the hip in spastic cerebral palsy. J Pediatr Orthop. 1984;4:52-4.

54. Hsu LC, Li HS. Distal hamstring elongation in the management of spastic cerebral palsy. J Pediatr Orthop. 1990;10:378-81.

55. Reimers J. Contracture of the hamstrings in spastic cerebral palsy. A study of three methods of operative correction. J Boyne Joint Surg Br. 1974;56:102-9.

56. Perry J. Distal rectus femoris transfer. Dev Med Child Neurol. 1987;29:153-8.

57. Gage JR, Perry J, Hicks RR, Koop S, Werntz JR. Rectus femoris transfer to improve knee function of children with cerebral palsy. Dev Med Child Neurol. 1987;29:159-66.

58. Strayer LM Jr. Recession of the gastrocnemius; an operation to relieve spastic contracture of the calf muscles. J Bone Joint Surg Am. 1950;32:671-6.

59. Hoke M. An operation for stabilizing paralytic feet. J Orthop Surg. 1921; 3:494-507.

60. Nather A, Fulford GE, Stewart K. Treatment of valgus hindfoot in cerebral palsy by peroneus brevis lengthening. Dev Med Child Neurol. 1984;26:335-40.
61. Majestro TC, Ruda R, Frost HM. Intramuscular lengthening of the posterior tibialis muscle. Clin Orthop Relat Res. 1971;79:59-60.

62. Green NE, Griffin PP, Shiavi R. Split posterior tibial-tendon transfer in spastic cerebral palsy. J Bone Joint Surg Am. 1983;65:748-54.

63. Hoffer MM, Barakat G, Koffman M. 10-year follow-up of split anterior tibia tendon transfer in cerebral palsied patients with spastic equinovarus deformity. J Pediatr Orthop. 1985;5:432-4.

64. Bleck EE. Forefoot problems in cerebral palsy-diagnosis and management. Foot Ankle. 1984;4:188-94

65. Dega W. [Transiliac osteotomy in the treatment of congenital hip dysplasia] Chir Narzadow Ruchu Ortop Pol. 1974;39:601-13. Polish.

66. Mubarak SJ, Valencia FG, Wenger DR. One-stage correction of the spastic dislocated hip. Use of pericapsular acetabuloplasty to improve coverage. J Bone Joint Surg Am. 1992;74:1347-57.

67. Staheli LT. Slotted acetabular augmentation. J Pediatr Orthop. 1981;1:321-7. 68. Chiari K. Medial displacement osteotomy of the pelvis. Clin Orthop Relat Res. 1974;98:55-71

69. Root L, Siegal T. Osteotomy of the hip in children: posterior approach. J Bone Joint Surg Am. 1980;62:571-5.

70. Dodgin DA, De Swart RJ, Stefko RM, Wenger DR, Ko JY. Distal tibial/fibular derotation osteotomy for correction of tibial torsion: review of technique and results in 63 cases. J Pediatr Orthop. 1998;18:95-101.

71. Mosca VS. Calcaneal lengthening for valgus deformity of the hindfoot. Results in children who had severe, symptomatic flatfoot and skewfoot. J Bone Joint Surg Am. 1995;77:500-12.

72. Dennyson WG, Fulford GE. Subtalar arthrodesis by cancellous grafts and metallic internal fixation. J Bone Joint Surg Br. 1976;58:507-10.

73. Rang M. Cerebral palsy. In: Morrissy RT, editor. Lovell and Winter's pediatric orthopaedics. 3rd ed. Philadelphia: Lippincott; 1990. p 465-506.

74. Bakheit AM, Severa S, Cosgrove A, Morton R, Roussounis SH, Doderlein L, Lin JP. Safety profile and efficacy of botulinum toxin A (Dysport) in children with muscle spasticity. Dev Med Child Neurol. 2001;43:234-8. Erratum in: Dev Med Child Neurol. 2001:43:357.

75. Galli M, Crivellini M, Santambrogio GC, Fazzi E, Motta F. Short-term effects of "botulinum toxin a" as treatment for children with cerebral palsy: kinematic and kinetic aspects at the ankle joint. Funct Neurol. 2001;16:317-23.

76. Mall V, Berweck S, Kirschner J, Herrmann J, Schelle A, Linder M, Michaelis U, Stein S, Korinthenberg R, Heinen F. Die Therapie spastischer Bewegungsstörungen im Kindesalter mit Botulinumtoxin A. Klin Neurophysiol. 2001;32:218-24.

77. Browne AO, McManus F. One-session surgery for bilateral correction of lower limb deformities in spastic diplegia. J Pediatr Orthop. 1987;7:259-61.

78. Wood $E$, Rosenbaum $P$. The gross motor function classification system for cerebral palsy: a study of reliability and stability over time. Dev Med Child Neurol. 2000;42:292-6.

79. Bleck EE. Locomotor prognosis in cerebral palsy. Dev Med Child Neurol. 1975;17:18-25

80. Watt JM, Robertson CM, Grace MG. Early prognosis for ambulation of neonatal intensive care survivors with cerebral palsy. Dev Med Child Neurol. 1989; 31:766-73.

81. Molnar GE, Gordon SU. Cerebral palsy: predictive value of selected clinical signs for early prognostication of motor function. Arch Phys Med Rehabil. 1976; 57:153-8.

82. da Paz Junior AC, Burnett SM, Braga LW. Walking prognosis in cerebral palsy: a 22-year retrospective analysis. Dev Med Child Neurol. 1994;36:130-4. 
Copyright of Journal of Bone \& Joint Surgery, American Volume is the property of Journal of Bone \& Joint Surgery and its content may not be copied or emailed to multiple sites or posted to a listserv without the copyright holder's express written permission. However, users may print, download, or email articles for individual use. 